
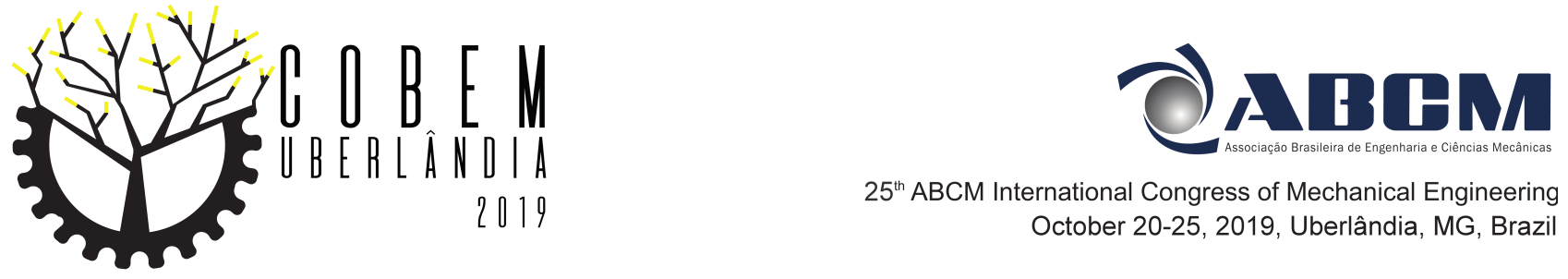

$25^{\text {th }} \mathrm{ABCM}$ International Congress of Mechanical Engineering October 20-25, 2019, Uberlândia, MG, Brazil

\title{
EXPERIMENTAL STUDY OF ATOMIZATION BY IMPINGING JETS OF LIQUID AND GELLED GREEN PROPELLANTS
}

\author{
Gabriel Silva Dias \\ José Carlos de Andrade \\ Gustavo Alexandre Achilles Fischer \\ Fernando de Souza Costa \\ Combustion and Propulsion Laboratory - LABCP \\ National Institute for Space Research - INPE \\ Rodovia Presidente Dutra, km 40, CEP 12.630-000 \\ Cachoeira Paulista/SP - Brazil \\ gabriel.dias@inpe.br
}

Abstract. Gelled propellants are an interesting option for rockets and missiles propulsion systems, since they combine high performance with facility of handling and storage. These characteristics are due to the shear thinning non-Newtonian behavior of gels. High shear rates can lead to extensive liquefaction of gelled fluids. This liquefaction offers the possibility to develop engines that can be throttled like liquid propellant engines. Impinging jet injectors are commonly used in propulsion systems applications since they can be easily manufactured and can provide good atomization and mixing characteristics within a short distance. Green propellants represent a low toxicity and high performance alternative to the conventional hazardous propellants. This work compares analytical solutions with images of the sheet shapes formed by the impingement of two round jets of water, liquid hydrated ethanol and gelled hydrated ethanol. Breakup lengths and maximum widths of the sheet shapes are determined as function of the Reynolds number. The analytical plotted sheet shapes have shown good agreement with experimental data for water and liquid hydrated ethanol, but not for gelled hydrated ethanol. The aspect ratio was approximately constant, around 2, for water and liquid hydrated ethanol, while for gelled hydrated ethanol the breakup length increased exponentially and the aspect ratio increased linearly with Reynolds number.

Keywords: atomization, impinging jet, green propellant, gelled propellant

\section{INTRODUCTION}

The development of propulsion systems will be more influenced in the future by increasing demands concerning more complex missions safety, and cost reduction. More complex mission demands are for example caused by more complex mission scenarios up to multiple swing-by maneuvers and trajectory changes in long-term missions, thrust variation on demand, and re-ignitability (Ciezki et al., 2015).

Liquid propellant rocket engines have been used as the primary propulsion system for many launch vehicles since the late 1920s. The performance of a rocket engine is determined not only by the selection of propellants but also by performance of the atomization process provided by the propellant injectors (Fischer, 2019).

Atomization is an essential process that occurs on the propulsion systems, it accelerates vaporization by breaking up the liquid or gelled fuel into droplets and distributes it throughout the combustion chamber. In atomization, the surface area of the liquid phase is increased until the process becomes unstable, leading to disintegration of the liquid interface into droplets. Small droplets are required to achieve rapid ignition and establish a flame front adjacent to the injection head. Large droplets take longer to burn and thus define the length of the combustion chamber (Ghafourian et al., 1991) (Khavkin, 2004). Atomization can be achieved by different injection methods such as dual orifice or coaxial jets, impinging jets, rotary and electrostatic (Ghafourian et al., 1991).

Impinging jets have been extensively studied since last century until nowadays (Deng et al. (2018), Negri and Ciezki (2016), Ramasubramanian et al. (2015), Connell et al. (2017), Yang et al. (2019)). Impinging jets are used by their easy of manufacture and simultaneous good atomization and mixing to achieve an efficient mixing and burning of propellants. The low-velocity impinging jets form a sheet in a plane perpendicular to that of the momentum vectors of the jets. Waves form on the surface of the sheet (Fig. 1a) and grow until the sheet is fragmented into ligaments, which eventually break into liquid drops (Fakhri et al., 2010).

The shape and the thickness of the sheet depend on the impingement angle, the jet diameter, velocity, and fluid physical properties. The atomization of the sheet produces droplets of such size and distribution as dictated by the thickness of the 
edge of the sheet and its orientation (Ibrahim and Przekwas, 1991).

Gelled propellants are homogeneous mixtures of a base liquid and a gelling agent. The beneficial combination of high performance and superior handling and storage characteristics merge the major advantages of both liquid and solid propulsion systems because of the non-Newtonian flow behavior of gels. Rocket engines using gelled propellants can be throttled and restarted, similar to engines with liquid propellants. On the other hand, gelled propellants will not spill through leaks, will hardly slosh in the tank and have a reduced vapor pressure in comparison to their base-fluid. In this respect gel propellant engines behave like solid-propellant motors (Ciezki et al., 2017).

To decrease air pollution occasioned by rocket launches and risks due to stockage and handle, recent research has been done to develop propellants that are environmental friendly, usually called as green propellants. These propellants are generally easier and safer to use than the traditional ones, and are likely to bring down the costs associated with propellant convey and storage (Aggarwal et al., 2015).

Therefore, this work aims to present an experimental study of impinging jets of green liquid and gel fluids. The collision geometry for water, liquid hydrated ethanol and gelled hydrated ethanol will be analyzed, and the sheet shape, breakup length and maximum width of the sheet (Fig. 1a) formed by the impact of two round jets will be compared.

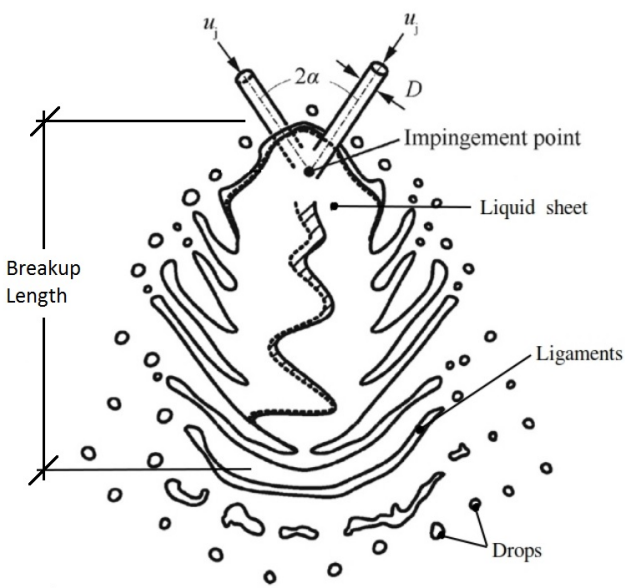

a)

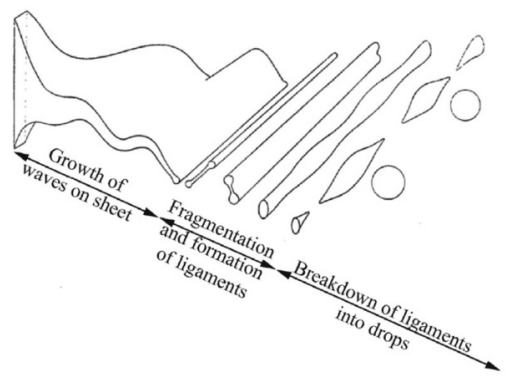

b)

Figure 1. General breakup process by two impinging jets of liquids. Adapted from Yang et al. (2019)

\section{METHODOLOGY}

Pictures of the sheet formed by the collision of two round jets of water, ethanol and gelled ethanol were taken in order to determine their shape, breakup length and maximum width (Fig. 1a). Results were obtained as function of the generalized Reynolds number for power law fluids, given by:

$$
R e_{P L}=\frac{\rho u_{g e l}^{2-n} D^{n}}{\mu\left[0.75+\left(\frac{0.25}{n}\right)\right]^{n} 8^{n-1}}
$$

where $\rho$ is the fluid density, $D$ is orifice diameter, $\mathrm{u}_{\text {gel }}$ is the gelled jet velocity, $\mu$ is viscosity, $n$ is the flow behavior index.

For Newtonian fluids, the generalized Reynolds number reduces to:

$$
R e=\frac{\rho u_{j e t} D}{\mu}
$$

where $u_{\text {jet }}$ is the liquid jet velocity.

To find a general solution for liquid sheets, Ibrahim and Przekwas (1991) conduct an analysis in polar coordinates of force balance on the edges of the sheet and found a solution as function of Weber number, as follow:

$$
r=W e \frac{D}{2} \frac{\beta e^{(1-\phi / \pi)} \sin ^{2} \psi}{4\left(e^{\beta}-1\right)}
$$

where $r$ is the radius (edge) of the sheet, We is the Weber number, $D$ is the jet diameter, $\phi$ the azimuthal angle, $\psi$ is the angle between the velocity vector and the local tangent of the sheet edge and $\beta$ is a parameter determined from mass and momentum conservation, derived from the impinging angle and can be numerically calculated from:

$$
\cos (\theta)=\left(\frac{e^{\beta}+1}{e^{\beta}-1}\right) \frac{1}{1+(\pi / \beta)^{2}}
$$


where $\theta$ is the half-impingement angle.

Considering $\psi$ as function of $\phi$ and $\theta$, Ibrahim and Przekwas (1991) proposed:

$\psi=\frac{\pi}{2} e^{\ln (2 \theta / \pi)(1-\phi / \pi)}$

The Weber number $(\mathrm{We})$ is a dimensionless number often used in analysing fluid flows where there is an interface between two different fluids, it is a measure of the relative importance of the inertia of the fluid compared to surface tension, given by:

$$
W e=\frac{\rho u_{j}^{2} D}{\sigma}
$$

where $\sigma$ is the surface tension.

Analogously to Reynolds number, Weber number can also be written for a power-law fluid (Mallory, 2012):

$$
W e_{P L}=O h_{P L}^{\frac{2}{2-n}} R e_{P L}^{\frac{2}{2-n}}
$$

where $O h$ is the Ohnesorge number $\left(O h=\mu /(\rho \sigma D)^{1 / 2}\right)$, a dimensionless number that relates the viscous forces to inertial and surface tension forces. The Ohnesorge number for a power-law fluid is given by (Mallory, 2012):

$$
O h_{P L}=\frac{k}{\left(\sigma^{(2-n)} \rho^{n} D^{(3 n-2)}\right)^{1 / 2}}
$$

where $k$ is the flow consistency index.

\subsection{Workbench}

The workbench contains gel and liquid tanks (Fig. 2), besides pressure transducers and control valves. A $N_{2}$ cylinder is used to provide pressures up to 20 bar, thus allowing feed gel or liquid through the injector. A Novus Fieldlogger (data acquisition device) was used to record differential pressure data during the tests. A Nikon D3100 digital camera with shutter speed 1/3200 seconds and external light was used to capture images. The camera's clock was synchronized with the data acquisition device for posterior analysis.

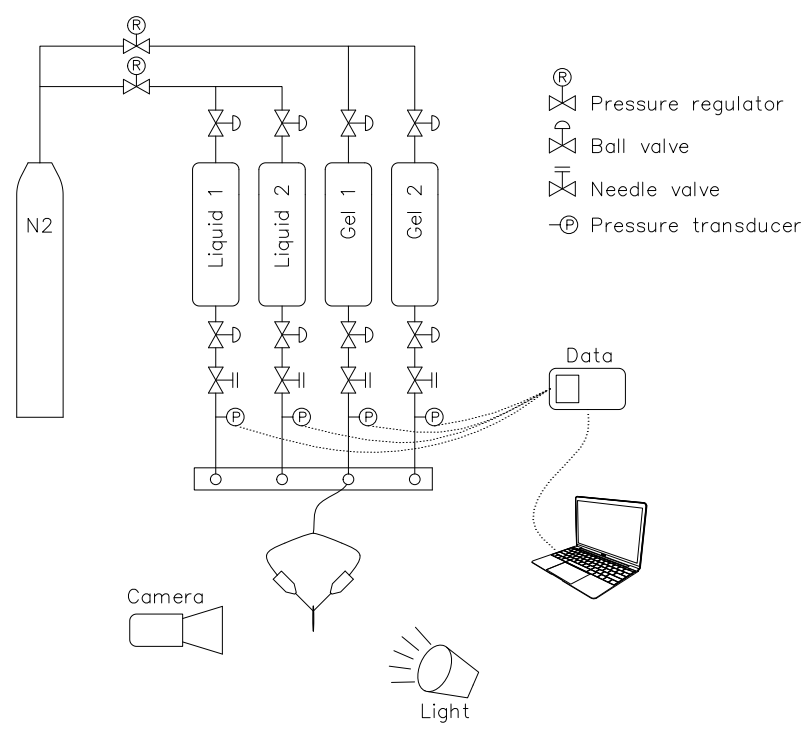

Figure 2. Schematic diagram of the experiment setup

\subsection{Injectors design}

Two inlet-chamfered jet injectors were made of Aluminium 6351 for atomization studies by impinging jets of liquids and gels, as depicted in Figure 3. The injector had orifice diameter $(D)$ of $0.8 \mathrm{~mm}$ and orifice length $(l)$ of $8.0 \mathrm{~mm}$, resulting in a ratio $l / D=10$.

An inlet chamfer can increase the discharge coefficient (Bergwerk, 1959). 


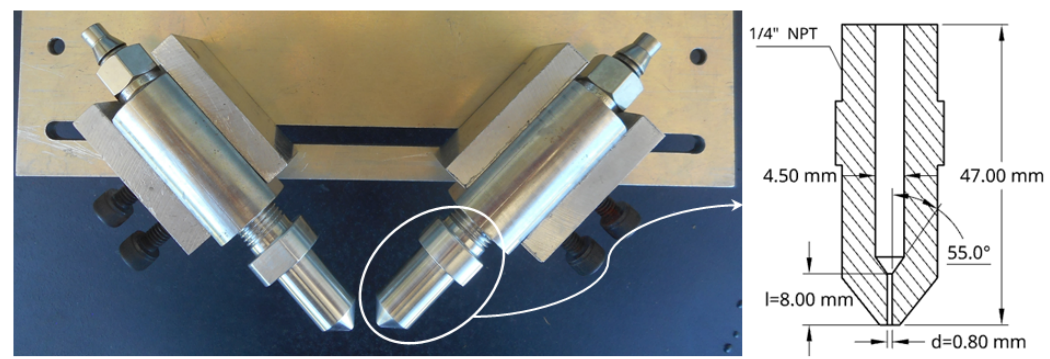

Figure 3. Impinging jets assembly and injectors design

\subsection{Working fluids}

Water, liquid hydrated ethanol and $72^{\circ}$ INPM gelled ethanol were used as working fluids.

Liquid hydrated $\left(92,6-93,8 \%\right.$ (w/w) ethanol has a specific mass of $809.3 \mathrm{~kg} / \mathrm{m}^{3}$, viscosity $1.2 \mathrm{cP}$ and $\sigma=0.0229$ $N / m$ at $20^{\circ} \mathrm{C}$. The physical properties of $72^{\circ}$ INPM gelled ethanol, with addition of gelling Carbopol ${ }^{\circledR}$ agent are shown in Table 1.

Table 1. Physical properties of gelled $72^{\circ}$ INPM ethanol

\begin{tabular}{|c|c|c|}
\hline Properties & Minimum & Maximum \\
\hline Alcohol content (w/w) - ${ }^{\circ}$ INPM & 69.55 & 75.27 \\
\hline Alcohol content (v/v) $-{ }^{\circ} \mathrm{GL}$ & 76.9 & 81.4 \\
\hline $\mathrm{pH}$ & 6 & 8 \\
\hline Density, $20^{\circ} \mathrm{C}$ & 850 & 860 \\
\hline Viscosity (cP) at rest, $20^{\circ} \mathrm{C}$ & $>12000$ & \\
\hline
\end{tabular}

Adapted from Fischer (2019).

To characterize the gelled working fluid, an Anton Paar rheometer model MCR 72 with spindle parallel plates of 25 $\mathrm{mm}$ diameter and $1 \mathrm{~mm}$ space between plates was used. A Peltier system was used for temperature control at $25^{\circ} \mathrm{C}$ during shear rate scanning.

Figure 4 shows the viscosity curve of gelled ethanol versus shear rate, adjusted for a power-law fluid. The parameters $k$ and $n$ are indicated.

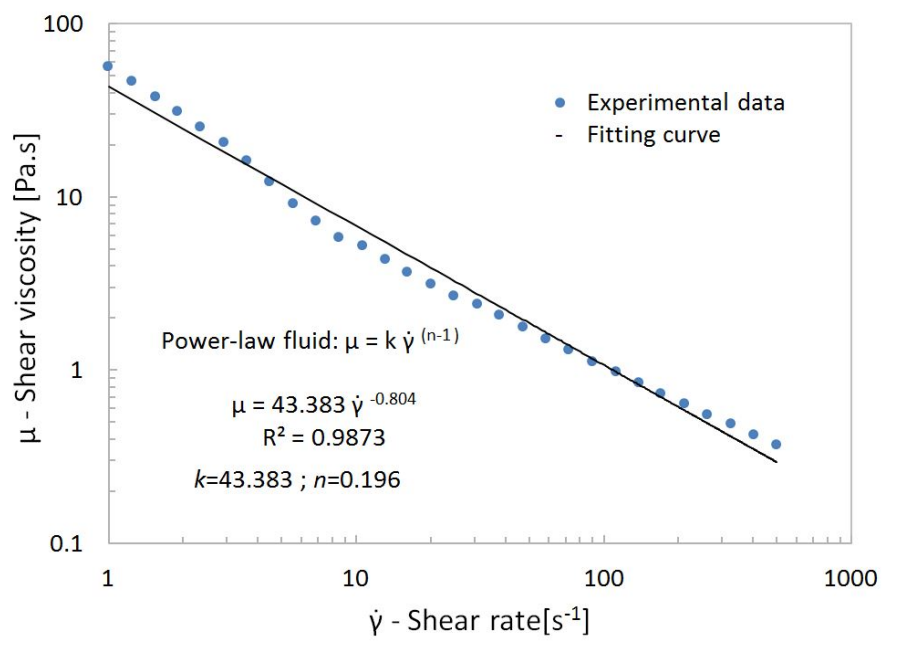

Figure 4. Rheological characterization of $72^{\circ}$ INPM gelled ethanol.

\section{RESULTS AND DISCUSSION}

Figure 5 shows a comparison between plotted sheets using Equations 3 to 5 and pictures, using water, hydrated ethanol and $72^{\circ}$ gelled ethanol INPM as working fluids. The impingement angle was $2 \theta=90^{\circ}$ and the pre-impingement jet length was $10 \mathrm{~mm}$. For the gelled ethanol the non-dimensional numbers of a power-law fluid was used (Eqs 1, 7 and 8). The 
surface tension of the gelled ethanol was considered the same as the liquid.

The analytical solution of Ibrahim and Przekwas (1991) is effective in describing sheet behavior for water and liquid ethanol, as shown in Figures 5a and 5b, once the breakup length and maximum width sheet are in good accordance with experimental data. For gelled ethanol the analytical model expects a much larger sheet shape than it is really found experimentally. This fact is related with the high generalized Weber number calculated for Figure 5c, which affects proportionally the sheet shape.

According to sheet breakup regimes, Li and Ashgriz (2006) argued that there are two major types of instability that can cause the breakup: aerodynamic waves and impact waves. Mainly about the aerodynamic waves, they listed two regimes of instability: Capillary (closed-rim sheet) and Kelvin-Helmholtz instability. In Figures 5a and 5b is possible to verify a sub-regime of Capillary instability classified as smooth sheet, on its edges the disturbance causes the local momentum force to be greater than the local surface tension force. These disturbances generate some bead-like shapes, which keep growing while moving along the edge. After growing, the beads form drops attached to the sheet edge by ligaments. The ligaments then disintegrate into smaller droplets after separation from the sheet (Li and Ashgriz, 2006).

For the closed sheet formed by gelled ethanol (Fig. 5c), Deng et al. (2018) argue that the lateral momentum of the sheet is relatively small when impinging momentum is small, as a result the sheet will converge to a point. Even though the sheet does not break, it's disturbed by waves. They argue that formation of the pattern called closed sheet depends on lateral momentum, damping of viscosity, and gel surface tension. That is, the inertial force is lower than viscous force and surface tension at the point of the maximum sheet width, and consequently the sheet is restrained and begins to converge from the point. In addition, there are no droplets produced around the rim of sheet unlike water and liquid ethanol. According Deng et al. (2018) surface tension and viscous damping are enough to prevent formation of droplets and ligaments, at the closed-rim regime.

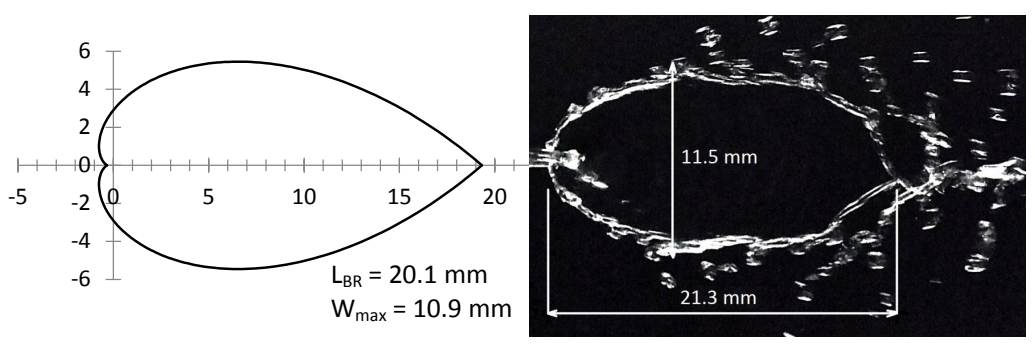

a) Water, $\operatorname{Re}=2159 ; \mathrm{We}=81 ; 2 \theta=90^{\circ} ; \mathrm{l} / \mathrm{D}=10$

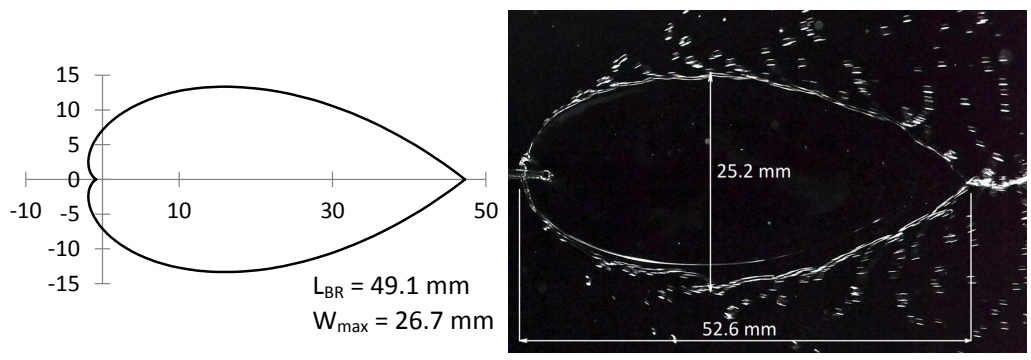

b) Ethanol, $\mathrm{Re}=1402 ; \mathrm{We}=198 ; 2 \theta=90^{\circ} ; \mathrm{I} / \mathrm{D}=10$

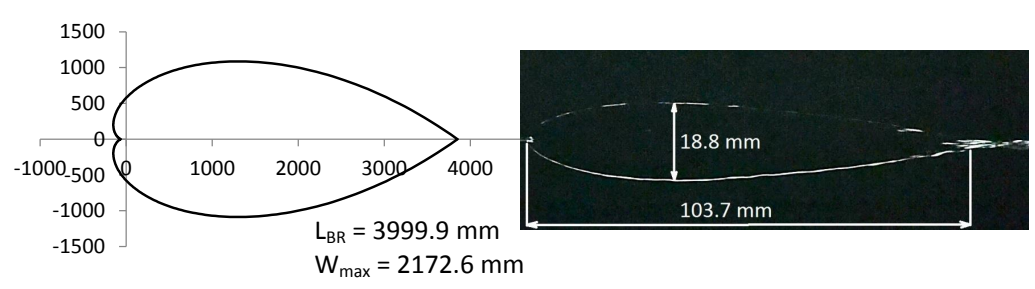

c) Gelled Ethanol, , $\operatorname{Re}_{\mathrm{PL}}=1416 ; \mathrm{We} \mathrm{PL}_{\mathrm{PL}}=16105 ; 2 \theta=90^{\circ} ; \mathrm{I} / \mathrm{D}=10$

Figure 5. Comparison between analytical plot and pictures 
Figure 6 shows the aspect ratio $\left(L_{B r} / W_{\max }\right)$ and the breakup length both as function of Reynolds number, for closedrim sheet regime. The measures were taken using a Matlab routine for image processing developed by Vásquez (2011).

Figure 6 a shows that water and liquid hydrated ethanol form sheet shapes with aspect ratios nearly constant, around 2 , in the range of Reynolds number considered. This value is close to the value 2.1 found by Baek et al. (2011) using water, for $2 \theta=90^{\circ}$ and $\mathrm{D}=0.7 \mathrm{~mm}$. For gelled ethanol, Figure 6a shows that the aspect ratio increases approximately linearly with the Reynolds number, and the sheet tends to stretch until breakup.

Figure $6 \mathrm{~b}$ indicates a linear increase of the breakup length of water and liquid hydrated ethanol and an exponential increase of the breakup length of gelled ethanol, with Reynolds number. This exponential behavior of the non-Newtonian sheet is probably due to the damping effect of viscosity which varies with shear rate along the sheet.
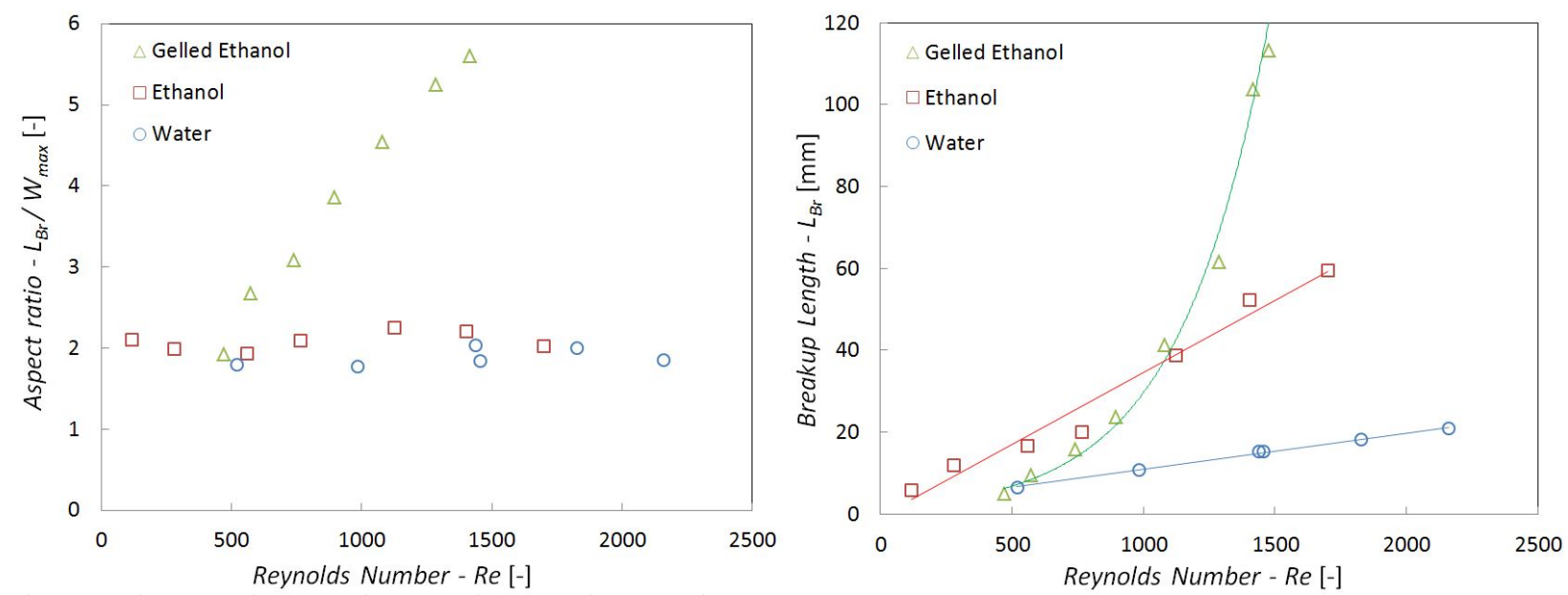

Figure 6. Aspect ratio and breakup length as function of Reynolds number

\section{CONCLUSION}

The sheet shapes formed by the impingement of two round jets of water, liquid hydrated ethanol and gelled ethanol were compared to theoretical results. Breakup lengths and maximum widths of the sheet formed by the collision of round jets were determined as function of the Reynolds number. The analytical solution for the sheet shape provided good accordance with experimental data for water and liquid hydrated ethanol, whereas in the case of gelled hydrated ethanol the analytical solution indicated a much larger sheet shape than experimental data. The aspect ratio was around 2 in the range of Reynolds number considered, for water and liquid hydrated ethanol, while for gelled hydrated ethanol the breakup length increased exponentially and the aspect ratio increased linearly with Reynolds number. This exponential behavior of the non-Newtonian sheet is probably due to the damping effect of viscosity which varies with shear rate along the sheet.

\section{ACKNOWLEDGEMENTS}

The authors acknowledge FAPESP for support through process 2016/21957-0 and CAPES for the M.Sc. scholarship granted to the first author.

\section{REFERENCES}

Aggarwal, R., Patel, I.K. and Sharma, P.B., 2015. "Green propellant: A study". International Journal of Latest Trends in Engineering and Technology (IJLTET), Vol. 6, No. 1, pp. 83-87.

Baek, G., Kim, S., Han, J. and Kim, C., 2011. "Atomization characteristics of impinging jets of gel material containing nanoparticles". Journal of Non-Newtonian Fluid Mechanics, Vol. 166, pp. 1272-1285.

Bergwerk, W., 1959. "Flow pattern in diesel nozzle spray holes". Proc. Inst. Mech. Eng., Vol. 173, No. 25 , pp. 655-660.

Ciezki, H.K., Negri, M. and Gernoth, A., 2015. "Advanced liquid and gelled propellants for rocket and ramjet propulsion”. International Journal of Energetic Materials and Chemical Propulsion, Vol. 2, No. 14, pp. 85-123.

Ciezki, H.K., Pinto, P.C., Hürttlen, J., Kirchberger, C., Stiefel, A., Kröger, P., Ramsel, J., Naumann, W., Schaller, U., Imiolek, A. and Weiser, V., 2017. "Overview on the german gel propulsion technology activities: Status 2017 and outlook". 7th European Conference for Aerospace Sciences (EUCASS2017), Milan, Italy.

Connell, T.L., Risha, G.A., Yetter, R.A. and Natan, B., 2017. "Hypergolic ignition of hydrogen peroxide/gel fuel impinging jets". Journal of Propulsion and Power, pp. 1-7. 
Deng, H., Feng, F. and Zhuo, C., 2018. "A simplified linear model and breakup characteristics of power-law sheet formed by a doublet impinging injector”. Proc. IMechE Part G: Journal Aerospace Engineering, Vol. 232, pp. $1035-1046$.

Fakhri, S., Lee, J.G. and Yetter, R.A., 2010. "Effect of nozzle geometry on the atomization and spray characteristics of gelled-propellant simultants formed by two impinging jets". Atomization and Sprays, Vol. 20, No. 12, pp. $1033-1046$.

Fischer, G.A.A., 2019. Atomização de Géis por Injetores Centrífugos e Jato-Centrífugos para Aplicações em Propulsão de Foguetes. Ph.D. thesis, National Institute for Space Research, São José dos Campos, Brazil.

Ghafourian, A., Mahalingam, S., Dindi, H. and Daily, J.W., 1991. "A review of atomization in liquid rocket engines". 29th Aerospace Sciences Meeting, Reno, Nevada, US.

Ibrahim, E.A. and Przekwas, A.J., 1991. "Impinging jets atomization”. Phys.Fluids A, Vol. 3, No. 12, pp. $2981-2987$.

Khavkin, Y.I., 2004. Theory and practice swirl atomizers. Taylor \& Francis, New York, 1st edition.

Li, R. and Ashgriz, N., 2006. "Characteristics of liquid sheets formed by two impinging jets". Physics of Fluids, Vol. 18, pp. $1-13$.

Mallory, J.A., 2012. Jet Impingement and Primary Atomization of non-Newtonian Liquids. Ph.D. thesis, Purdue University, West Lafayette, Indiana, USA.

Negri, M. and Ciezki, H.K., 2016. "Atomization of viscoelastic fluids with an impinging jet injector: morphology and physical mechanism of thread formation". Atomization and Sprays, Vol. 27, pp. 319-336.

Ramasubramanian, C., Notaro, V. and Lee, J.G., 2015. "Characterization of near-field spray of nongelled- and gelledimpinging doublets at high pressure". Journal of Propulsion and Power, pp. 1-11.

Vásquez, R.A., 2011. "Desenvolvimento de um injetor centrífugo dual para biocombustíveis líquidos". MSc dissertation, National Institute for Space Research, São José dos Campos, Brazil, SP, Brazil.

Yang, L., Fu, Q., Zhang, W., Du, M. and Tong, M., 2019. "Spray characteristics of gelled propellants in novel impinging jet injector”. Journal of Propulsion and Power, Vol. 29, pp. 104-114.

\section{RESPONSIBILITY NOTICE}

The authors are the only responsible for the printed material included in this paper. 